\title{
UN MOMENTO NO DISCURSIVO \\ EN EL RAZONAMIENTO JURÍDICO, UNA APROXIMACIÓN DE MATRIZ ARISTOTÉLICA*
}

\author{
A NON-DISCURSIVE MOMENT IN LEGAL REASONING, \\ AN ARISTOTELIAN APPROACH
}

\author{
Pedro Rivas PALÁ**
}

\section{Resumen:}

Este trabajo trata de mostrar que en el razonamiento práctico hay al menos un elemento no discursivo. En segundo lugar, sostiene que ese elemento, aunque no sea discursivo, no es irracional. El empeño de la lógica jurídica y de las teorías de la argumentación jurídica es tratar de explicar cada uno de los pasos que debe dar quien razona en el ámbito del derecho. En la formación y construcción de los fundamentos de una decisión existen aspectos donde no hay discurso, sino más bien hallazgo de la solución o de los elementos necesarios para alcanzar la solución. Por desgracia, todo esto ha sido caracterizado en nuestro lenguaje habitual como intuición, en el mejor de los casos, o de empatía o instinto. Por lo anterior, vamos a intentar mostrar que tales elementos no discursivos son máximamente racionales. Es decir, que lejos de expresar lo inexpresable por irracional e incomunicable, se presentan paradójicamente como momentos donde la razón preside el acceso a la realidad y lo hace de manera certera y precisa.

\section{Palabras clave:}

Razonamiento práctico; synesis; Aristóteles; argumentación jurídica.

${ }^{*}$ Artículo recibido el 14 de noviembre de 2018 y aceptado para su publicación el 23 de noviembre de 2019.

** Universidad de La Coruña, pedro.rivas@udc.es.

Problema. Anuario de Filosofía y Teoría del Derecho, núm. 14, enero-diciembre de 2020, pp. 315-344 Ciudad de México, ISSN 2007-4387, se distribuye bajo una Licencia Creative Commons Reconocimiento-No Comercial-Sin Derivados 4.0 Internacional (CC BY-NC-ND 4.0). 


\title{
PEDRO RIVAS PALÁ
}

\begin{abstract}
:
In a first stage, this paper tries to show that in practical reasoning there is at least one non-discursive element. Then, it maintains that this element, although it is not discursive, is not irrational. The aim of the legal logic and legal argumentation theories is to try to explain each of the steps that must be taken by the person who reasons in the field of Law. In the formation and construction of the foundations of a decision there are aspects where there is no discourse, but rather a finding of the solution or the necessary elements to reach a solution. Unfortunately, all this has been characterized in our usual language as intuition, empathy or instinct. Therefore, we will try to show that such non-discursive elements are maximally rational. That is to say, far from expressing the inexpressible as irrational and incommunicable, they paradoxically appear as moments where reason presides the access to reality in an accurate and accurate manner.
\end{abstract}

\section{Keywords:}

Practical Reasoning; Synesis; Aristotle; Legal Argumentation. 
SUMARIO: I. Introducción. II. Los términos del problema. III. La synesis aristotélica. IV. La synesis y la prudencia. V. El carácter dialógico de la synesis. VI. La naturaleza de la synesis. VII. La synesis en la teoría del conocimiento jurídico. VIII. Excursus: una posible traducción. IX. Bibliografía.

\section{INTRODUCCIÓN}

La finalidad de este trabajo es mostrar que hay al menos un elemento no discursivo en el ámbito del razonamiento práctico, y tratar de comprenderlo. En segundo lugar, se trata de mostrar que ese elemento, aunque no sea discursivo, no es irracional. En este sentido, el razonamiento jurídico, como ejemplo de juicio práctico, prudencial en este caso, tendrá también elementos o momentos no discursivos. Esta tesis puede resultar desconcertante porque precisamente el empeño de la lógica jurídica y de las teorías de la argumentación jurídica es tratar de explicar cada uno de los pasos que debe dar quien razona en el ámbito del derecho. Para ello, se nos muestran también los errores a evitar en forma de incoherencias, falacias, déficits, inconclusiones, etcétera. La manera de comprender y sobre todo de fiscalizar la argumentación en derecho pasa concretamente por la descripción del discurso jurídico, entendido como una concatenación de razones que fundamentan una decisión.

Es evidente que uno de los puntos de partida del razonamiento jurídico, el propio derecho objetivo, no se plantea discursivamente porque no necesita justificación. Es más, por eso es un punto de partida. Pero no nos referimos a esta cuestión. A lo que se apunta es a que en la formación y construcción de los fundamentos de una decisión existen aspectos donde no hay discurso, sino más bien hallazgo (inventio) de la solución o de los elementos necesarios para alcanzar la solución. Por desgracia, todo esto ha sido caracterizado en nuestro lenguaje habitual como intuición, en el mejor de los casos, o de empatía o instinto. Tales palabras nos remiten en su uso común al mundo de lo irracional, o al menos de lo inexplicable, que es aquel que pretendemos evitar a toda costa. Hablar de intuición nos lleva a ámbitos como el de la creación artística, rodeados de misterio para 
el común de los mortales, y, en todo caso, inaccesibles. Otras expresiones propias del hablar coloquial emplean metáforas (tener buen ojo, llevarlo en la sangre, darse bien algo), lo que nos conduce de nuevo hacia ámbitos poéticos y, por tanto, carentes de explicación científica. Por lo anterior, se hace necesario adelantar en este punto que vamos a intentar mostrar que tales elementos no discursivos son precisamente máximamente racionales. Es decir, que lejos de expresar lo inexpresable por irracional e incomunicable, se presentan paradójicamente como momentos donde la razón preside el acceso a la realidad y lo hace de manera certera y precisa.

\section{LOS TÉRMINOS DEL PROBLEMA}

El origen de la cuestión surge de considerar que la mayor parte de las decisiones que tomamos en el ámbito práctico carecen de proceso deliberativo. Con esto no me estoy refiriendo ni única ni principalmente al género de acciones que hacemos ordinariamente y que ejecutamos de manera maquinal o por costumbre, como se acostumbra a decir. Se trata de algo diferente. Por ejemplo, en las relaciones que se dan en el terreno educativo (sea institucional o familiar), en el mundo laboral, en las relaciones médico-paciente o en el del juego, tomamos decisiones de manera constante, y se hacen de modo inmediato, muchas veces de forma reactiva a las acciones ajenas. La inmediatez de nuestra acción tiene que ver con que se trata de acciones que no pueden esperar más tiempo a ser llevadas a cabo, o simplemente porque no parecen a priori tan graves como para requerir una deliberación. Por ejemplo, toda acción de una madre o de un padre ante sus hijos, especialmente cuanto más pequeños sean, es de alguna manera educativa. Más aún si tiene que ver con lo que los hijos quieren, hacen o piden. Con sus numerosas variaciones de edad, número, entorno, etcétera, es fácil caer en la cuenta de la relevancia de cada acción de un padre o una madre en la educación y formación de sus hijos. En el terreno de las relaciones laborales, cada acción repercute muchas veces en las personas con las que trabajamos, sean superiores, iguales, subordinadas, clientes, proveedores, etcétera. Como en el ejemplo anterior, la relevancia de dichas accio- 
nes será variada, pero en todo caso hay detrás algún género de decisión por parte del agente. Por último, por su relevancia actual y por lo mucho que ha sido estudiado, vale la pena detenerse en las decisiones médicas de relevancia ética. Si bien es cierto que muchas de ellas cuentan con protocolos de actuación previos, y otras se pueden remitir a comités de ética hospitalaria, quedan a mitad de camino una considerable cantidad de situaciones donde no hay ni protocolo ni comité, o donde hay que interpretar una regla de tales protocolos. Estamos ante acciones con un importante componente ético, del que dependen bienes ajenos, y que dependen de la capacidad del médico para hacerse cargo de circunstancias ajenas. Por poner un ejemplo, el deber de facilitar el consentimiento informado depende, en gran medida, de comprender a quién se le está informando y cuál es la información que requiere recibir, incluso evaluar muchas veces las capacidades y condiciones de quien tiene que dar el consentimiento. En estos ejemplos, no se escapa la dimensión ética de nuestras acciones, pues en ellas se busca el bien ajeno (el del hijo, o el bien común de la empresa o de la sociedad, el del paciente), que es en muchos casos un bien propio (ser buen padre, buena madre, buen trabajador, buen médico).

En otro tipo de acciones, como el juego, se pone de manifiesto de manera quizá más patente esta necesidad de la inmediatez de la acción. En la medida en que el número de jugadores es mayor, son más numerosos los elementos a tener en cuenta al decidir, y en la mayoría de los deportes, como ejemplo de juegos, no hay tiempo para deliberar sobre la propia acción a desarrollar. Con todo, en el caso del juego, el aspecto ético no queda tan claro como en los ejemplos anteriores. Pero se remarca más la idea de inmediatez.

A mi modo de ver, lo que llama la atención es que a pesar de la dificultad que el agente debe afrontar por la ausencia de tiempo, somos capaces de identificar a quienes toman decisiones de este género de manera correcta. En efecto, las consecuencias o los resultados de dichas acciones se ponen de manifiesto en las demás personas; por ejemplo, en el carácter y forma de ser de los hijos, en la vida de quienes comparten un lugar de trabajo, en los beneficios de la empresa o en el servicio público que se presta, en los resultados del juego que se practique. Eso hace que hablemos de buena madre, buen padre, 
buen trabajador, buen médico, y, en un sentido diferente, buen jugador. Y de hecho si discutimos a la hora de calificar así a las personas o a uno mismo, es porque de alguna manera pensamos que se puede ser bueno, excelente, óptimo, en esas acciones.

Lo que se acaba de explicar acerca de la educación, del trabajo, de la práctica de la medicina o del juego puede extenderse a otros sectores de nuestra acción en otros tipos de relaciones interpersonales (afectivas, económicas, de vecindad, etcétera). Pareciera que el acierto que se da en tales acciones tiene que tener un origen singular cuando ocurre que la mayoría de tales acciones son propias de la inmediatez. Esta inmediatez se percibe más claramente cuando muchas veces son reactivas a una situación determinada que no se espera. Pero no hace falta que sea reactiva a nada para que la decisión no lleve detrás una deliberación.

Ahora bien, la ausencia de deliberación no significa que la acción no sea racional. Es más, el acierto en tales acciones muestra por el contrario que se trata de decisiones máximamente racionales. No sólo eso, sino que el agente es capaz a posteriori de explicar el sentido de su decisión, dando buenas razones de su curso de acción, que son compartidas por quienes le escuchan. Habitualmente, además, el agente no acierta por ser capaz de tomar en consideración todos los elementos involucrados, sino precisamente por focalizarse en la razón relevante para actuar como lo ha hecho. Cabe entonces preguntarnos qué es lo que hay en el ser humano que lo hace capaz de obrar así, sin un proceso de deliberación racional y, sin embargo, con un innegable acierto. Como se ve, nos encontramos ante aspectos no discursivos de nuestras decisiones prácticas. Las expresiones que se mencionaban al principio, como tener intuición o capacidad empática o las más claramente metafóricas, no pretenden ser explicativas de nada, y más bien expresan nuestra aparente incapacidad para comprender racionalmente nuestras acciones. Ahora bien, si son exitosas habitualmente y el agente puede justificarlas, no tiene sentido pensar que son precisamente irracionales.

Con todo, hay que señalar, antes de seguir, que no parece acertado relacionar estas acciones con los instintos humanos. Lo característico del ser humano es precisamente la carencia casi completa de instintos, la plasticidad de los mismos y la necesidad de aprendizaje 
que debe acompañarlos. En este punto, la obra de Arnold Gehlen sigue siendo una referencia clara e insoslayable. En efecto, lo que llama la atención al pensador alemán es la posibilidad de existencia de un ser como el humano que está expuesto a la descomunal capacidad de error y perturbabilidad de la conciencia. Y al mismo tiempo la falta en el mismo ser de una dotación de instintos que funcionen con seguridad. ${ }^{1} 0$ dicho de otro modo, cómo hace para mantenerse simplemente en vida un ser así, con esa concreta constitución corporal. ${ }^{2}$ Y es que dicha constitución lo muestra ante todo como un ser de carencias, sumamente imperfecto, e incluso imposible, paradójico en su corporalidad en comparación con el animal. ${ }^{3}$ Morfológicamente, en sentido biológico, el ser humano se caracteriza por su no adaptación, no especialización y primitivismo. Dentro de las condiciones naturales, originales y primitivas, hace ya mucho tiempo que se hubiera extinguido. En definitiva, desde el punto de vista orgánico es un ser carente de medios, carente de instintos, dejado a sí mismo, ${ }^{4}$ a tal punto que se pregunta cómo puede vivir un ser biológicamente monstruoso como el ser humano, un ser que no es comparable con ningún otro animal. ${ }^{5}$

Lo anterior le lleva a rechazar toda aproximación al ser humano que parta del esquema según el cual compartimos los instintos con los animales, y es la inteligencia lo que nos distingue de ellos. En realidad, existe una diferencia estructural que lo impregna todo. ${ }^{6}$ Por eso ni siquiera se puede transferir el concepto de instinto propio de los animales al ser humano. ${ }^{7}$ La singular relación en el ser humano entre inteligencia y biología en el ser humano fue señalada desde la antigüedad. En esa línea se inscribe el conocido pasaje aristotélico donde afirma que aunque ya Anaxágoras sostuvo que el hombre es el más inteligente de los animales porque tiene manos, en realidad

1 Gehlen, A., El hombre: su naturaleza y su lugar en el mundo (1940), trad. de Fernando-Carlos Vevia Romero, Salamanca, Sígueme, 1987, p. 14.

2 Ibidem, pp. 17 y 18.

3 Ibidem, p. 22.

4 Ibidem, pp. 37 y 38.

5 Ibidem, p. 40.

6 Ibidem, pp. 24 y 25.

7 Ibidem, p. 29. 
PEDRO RIVAS PALÁ

habría que decir que tiene manos por ser el más inteligente de los animales. $^{8}$

\section{LA SYNESIS ARISTOTÉLICA}

Aristóteles habla en la Ética a Nicómaco de unas disposiciones para saber discernir lo que es objeto de la prudencia. ${ }^{9}$ Una de ellas puede darnos la explicación del problema que hemos planteado. Con todo, es necesario ubicar, aunque sea de manera breve y comprimida, el sentido aristotélico de prudencia.

Para introducir sucintamente la visión aristotélica de la prudencia hay que comenzar por recordar su distinción entre los objetos del conocimiento humano. "Lo que es objeto de ciencia es necesario. Luego es eterno, ya que todo lo que es absolutamente necesario es eterno, y lo eterno, ingénito e imperecedero. Además toda ciencia parece susceptible de ser enseñada, y todo lo que es objeto de ella, de ser aprendido". ${ }^{10}$ En el lado opuesto, "entre las cosas que pueden

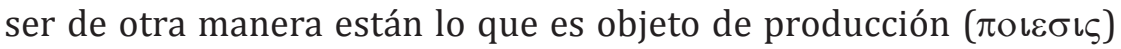
y lo que es objeto de acción $(\pi \rho \alpha \xi \iota \varsigma)$ ". ${ }^{11}$ Esta última es objeto de la prudencia $(\phi \rho \circ v \varepsilon \sigma \iota \varsigma)$. En efecto, cuando Aristóteles habla de acción $(\pi \rho \alpha \xi \iota \varsigma)$ se refiere a aquellas acciones cuyo fin es hacerlas bien. ${ }^{12} \mathrm{Y}$ en el caso de los seres humanos se trata de vivir bien, y en ese caso el fin de la praxis humana no es distinto de ella misma. ${ }^{13}$

Pero no solamente se trata de realidades no necesarias, sino que también hay otro rasgo de importancia. En concreto, refiriéndose a la prudencia, afirma: "Que la prudencia no es ciencia es evidente. En efecto, se refiere a lo más particular, como se ha dicho, porque lo práctico es de esta naturaleza”. ${ }^{14}$ Más claramente pone en relación

8 De partibus animalium, IV 10, 686b 5ss.

9 Ética a Nicómaco, VI 11, 1143a29-30. Se emplea la traducción de Julián Marías y María de Araujo (1949), Madrid, Centro de Estudios Constitucionales, 1994. A partir de ahora se cita EN y la numeración de la edición de Bekker.

10 EN, 1139b 23-25.

11 EN, 1140a 1-2.

12 EN, 1139b 3-4.

13 EN, $1140 \mathrm{~b} 7$.

14 EN, 1142a 30. 
los caracteres de particularidad, practicidad y la índole de acción: "Tampoco versa la prudencia exclusivamente sobre lo universal, sino que tiene que conocer también lo particular, porque es práctica y la acción tiene que ver con lo particular". ${ }^{15}$

Sin embargo, Aristóteles no renuncia a la condición de verdad cuando se trata del conocimiento no científico. Por ejemplo, cuando afirma que "del entendimiento teorético y no práctico ni creador, el bien y el mal son, respectivamente, la verdad y la falsedad, mientras que el bien de la parte intelectual pero práctica es la verdad que está de acuerdo con el deseo recto". ${ }^{16}$ Con todo, en este caso nos encontramos ante una verdad que no está separada de la utilidad, porque "el presente tratado no es teórico como los otros pues no investigamos para saber qué es la virtud, sino para ser buenos, ya que en otro caso sería totalmente inútil". ${ }^{17}$ Por eso, "con razón se dice que realizando acciones justas se hace uno justo... Y sin hacerlas ninguno tiene la menor probabilidad de llegar a ser bueno". ${ }^{18}$ Como la teoría se ocupa de lo que existe ya por sí mismo, no posee la virtud de realizar bien alguno, y así "la reflexión de por sí no pone nada en movimiento, sino la reflexión orientada a un fin y a una práctica". ${ }^{19}$ Por eso, en este caso la verdad no podrá consistir en adecuación alguna, por la sencilla razón de que carecemos de un objeto que aparezca por sí, porque estamos ante una realidad que tenemos que hacer surgir nosotros mismos. La verdad práctica es una verdad operativa. Es algo que ha de ser hecho, producido, realizado, de manera operativa. La verdad práctica debe tener ella misma carácter de praxis. Con frase precisa, aunque de complicada traducción, lo ha explicado el Estagirita: "Las cosas que hay que aprender a hacer, las aprendemos haciéndolas". 0 en traducción más libre: "Para saber lo que tenemos que hacer hay que hacer lo que queremos saber". ${ }^{20}$

De ahí que Aristóteles sostiene que estamos ante un saber acerca del propio sujeto: "el que sabe sobre uno mismo y actúa en conse-

\footnotetext{
15 EN, 1141b 15.

16 EN, 1139a 30.

17 EN, 1103b 26-29.

18 EN, 1105b 9-12.

19 EN, 1139a 35.

20 EN, 1103a 32 y 33.
} 
cuencia es prudente". ${ }^{21}$ El deber-ser aparece como incluido en el ser, que en los seres vivos consiste en vivir, y en los seres vivos racionales consiste en vivir conforme a la razón; es decir, en praxis, en actuar racional. Para ello será necesario considerar los medios y los fines de la acción, y deliberar sobre ellos de una manera buena, que "consiste en una especie de rectitud"22 que debe ser "conforme a lo conveniente para el fin aprehendido por la verdadera prudencia". ${ }^{23}$

Nos queda, por último, tratar de distinguir el conocimiento prudencial del artístico o técnico $(\tau \varepsilon \chi \vee \eta)$. Coinciden en ser saberes previos que guían y determinan la acción, y en que su objeto no es algo que siempre es como es. En ambos casos se echa mano de un saber previo para elegir bien los medios para resolver una situación concreta. Sin embargo, "los llamamos prudentes cuando razonan bien con vistas a algún fin bueno de los que no son objeto de ningún arte $(\tau \varepsilon \chi \vee \eta) "{ }^{24}$ La diferencia entre tales fines queda más clara cuando afirma que "el fin de la producción es distinto de ella, pero el de la acción no puede serlo: la buena actuación misma es un fin". ${ }^{25}$

Corresponde ya presentar el texto en el que Aristóteles habla de la disposición relevante. Para ello vamos a mantener el término sin traducir. Por lo demás, el resto del texto no parece presentar lecturas distintas, salvo alguna excepción. Vamos a echar mano de una de las traducciones comúnmente empleadas, ${ }^{26}$ aunque no sea la única de las confiables.

La synesis ( $\sigma u v \varepsilon \sigma \iota \varsigma)$ y la buena synesis ( $\varepsilon \cup \sigma u v \varepsilon \sigma \iota \alpha)$, en virtud de las

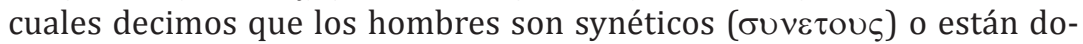
tados de buena synesis, no son en absoluto lo mismo que la ciencia o la opinión (en este caso, todos serían synéticos), ni son tampoco una de las ciencias particulares, como la medicina sobre lo concerniente a la salud o la geometría sobre las magnitudes, porque la synesis no se aplica a lo

${ }^{21} \mathrm{EN}, 1141 \mathrm{~b} 33$.

22 EN, $1142 \mathrm{~b} 10$.

23 EN, $1142 \mathrm{~b} 33$.

24 EN, 1140a 28 y 29.

25 EN, 1140b 5-7.

26 En concreto usamos la de Julián Marías y María de Araujo, Madrid, Instituto de Estudios Políticos, 1949, que cuenta con numerosas reimpresiones. 
que es siempre e inmóvil, ni lo que de un modo u otro llega a ser, sino a lo que puede presentar dificultades y ser objeto de deliberación. Por tanto, se aplica a lo mismo que la prudencia ( $\phi \rho \circ v \varepsilon \sigma \iota \varsigma)$, pero no son lo mismo synesis y prudencia. En efecto, la prudencia es normativa: qué se debe hacer o no, tal es el fin que se propone.; mientras que la synesis es sólo discriminativa ( $\chi \rho \iota \tau \iota x \eta$, "capaz de juzgar" en la traducción de Gredos), pues son lo mismo synesis y buena synesis, synéticos y dotados de buena synesis. La synesis no consiste en tener prudencia ni en alcanzarla, sino que, lo mismo que el aprender se le llama synienai ( $\sigma u v \iota \varepsilon v \alpha \iota$ ) tratándose de la ciencia, así también la synesis es lo que se ejercita en la opinión para juzgar las cosas que son objeto de la prudencia cuando habla otro ("cuando alguien habla acerca de ellas" en la traducción de Gredos), y para juzgar rectamente, pues "bien" es lo mismo que "rectamente". Y de ahí le viene el nombre de synesis en virtud del cual se habla de hombres dotados de buena synesis, de la synesis que se ejercita en el aprender; en efecto al aprender lo llamamos muchas veces syneinai (Ética a Nicómaco, VI 10, 1142b35-1143a18).

\section{LA SYNESIS Y LA PRUDENCIA}

Después de ver los textos aristotélicos, y para comprender el sentido de la synesis, corresponde tratar su relación con la prudencia. Para ello, vamos a detenernos en tres rasgos de dicha relación, a partir, en primer lugar, de los comentarios que Tomás de Aquino hace a estos pasajes de la Ética a Nicómaco. En primer lugar, la diferencia entre ambas parece clara, toda vez que "la prudencia es preceptiva, en cuanto que su fin es determinar lo que conviene realizar o no, mientras la synesis es sólo judicativa". ${ }^{27}$ En segundo lugar, son virtudes distintas, toda vez que sus actos son diferentes, ${ }^{28}$ al punto de denominar a la synesis como virtud adjunta de la prudencia. ${ }^{29} \mathrm{La}$ synesis no es el saber más alto sobre lo práctico porque la prudencia implica mayor saber, por eso, la synesis se ordena a la prudencia. ${ }^{30}$ En tercer lugar, y en continuidad con lo anterior, "la prudencia

27 In Ethicam, VI, lect. 9, n. 6.

28 S. Th., II-II, q. 53, a. 3, c.

${ }^{29}$ S. Th., II-II, q. 48, a. 1, c.

30 In III Sent. d. 33, q. 3, a. 1, qc. 3, c. 
es más eminente que la synesis, del mismo modo que la synesis lo es más que la eubulia, porque la inquisición se ordena al juicio como al fin, y el juicio se ordena al precepto". ${ }^{31}$ La prudencia es por tanto un hábito posterior a la synesis y superior a él. Por eso mismo, la prudencia no nace de la synesis, ya que lo superior no procede de lo inferior. ${ }^{32}$

Con respecto al primero de los rasgos, los comentadores más recientes inciden de una forma u otra en esa distinción. Hay quien ha llamado la atención sobre la mención que hace Aristóteles de que el objeto del juicio de la synesis tiene que ver con las acciones y elecciones de los otros. Por eso, se trataría meramente de un juicio sobre algo hecho por otro y que ya ha ocurrido, lo que significa que el que juzga no se compromete plenamente en el discurso práctico, cosa que sí ocurre con la prudencia. El que posee synesis es solamente un crítico perceptivo y atento. ${ }^{33}$ Algo similar se expresa al afirmar que la synesis es apreciativa, no imperativa. Por eso, el acto de la synesis no es eminentemente ético, porque valora en orden a la opinión y no a la acción, ${ }^{34}$ mientras que la prudencia no se ejercita de manera meramente intelectual. ${ }^{35} \mathrm{Y}$ es que aunque ambas tratan de lo agible, sin embargo, la synesis capacita para juzgar bien, mientras que a la prudencia pertenece el fin y el complemento, el llevar a término, es decir, mandar lo que procede para actuar. ${ }^{36}$ Se puede, por tanto, tener synesis y no pasar a la acción. ${ }^{37}$ La synesis es descrita entonces como una capacidad o disposición crítica, reflexiva, sobre lo práctico y contingente. Lo propio de ella es diferenciar, discriminar, discer-

31 In Ethicam, VI, lect. 9, n. 6.

32 In Ethicam, VI, lect. 9, n. 4.

33 Louden, R. B., "What is Moral Authority? Eubulía, synesis y gnome vs. frónesis", Ancient Philosophy 17 (1997), pp. 112 y 113.

34 Zagal, H., "Sýnesis, euphyía y anchínoia en Aristóteles. Algunas habilidades para el conocimiento del singular", Anuario Filosófico 32 (1999), p. 136.

35 Long, Ch. P., "The ontological reappropiation of phronesis", Continental Philosophy Review 35 (2002), p. 45.

36 Sellés, J. F., Los hábitos intelectuales según Tomás de Aquino, Pamplona, EUNSA, 2008, p. 348.

37 Ibidem, p. 351. 
nir lo particular. ${ }^{38} \mathrm{Su}$ acto destaca la mejor posibilidad factiva sobre las demás. ${ }^{39}$ El objeto de ambos es el mismo, pero sólo la prudencia es imperativa y ejecutiva. La synesis no equivale a decidirse, no implica necesariamente la ejecución del juicio, sino que permanece en el ámbito del pensamiento. ${ }^{40} 0$ dicho de otra manera, es la habilidad de comprender, considerar y juzgar cuestiones de relevancia ética en las que no estamos involucrados personalmente como agentes, ${ }^{41}$ porque estamos juzgando acciones ajenas (pasadas o futuras) o acciones propias pasadas. ${ }^{42}$

En relación con el segundo de los rasgos, hay diferentes enfoques acerca de si la synesis se ordena a la prudencia y en qué sentido. Pareciera entonces que la synesis sería un paso en el desarrollo de la prudencia. ${ }^{43}$ La synesis precede a y posibilita la prudencia, ${ }^{44} \mathrm{y}$, en este sentido, todo prudente tiene synesis, pero no todo aquel que tiene synesis es prudente. ${ }^{45}$

Sin embargo, hay quien, aun reconociendo que la synesis es independiente en cierto sentido de la prudencia, sostiene que no se trata de un paso preliminar. La synesis, en efecto, inquiere y razona como la prudencia, pero no prescribe; en realidad, le falta la esencial conexión con el deseo, que es propia de la prudencia. Por eso mismo, no discierne sobre la acción que queremos o podemos hacer, sino sobre la situación práctica inespecífica. Sin el deseo, para Aristóteles, no hay deliberación práctica singular y, por tanto, no hay elección ni acción. ${ }^{46}$ En efecto, sin los apetitos las ideas son ineficaces; por eso la

38 Rodrigues Montes D’Oca, F., "Prudencia e astucia na ética aristotélica: um estudo sobre as capacidades intelectuais que acompanham a prudencia", Controversia 5 (1) (2009), p. 14.

39 Sellés, J. F., op. cit., p. 352.

40 Zagal, H., "Apetito recto, prudencia y verdad práctica. Las pautas de la eupraxía en la Nicomáquea”, Metafísica y Persona 5 (9) (2013), p. 100.

41 Simon, A., "Sunesis as Ethical Discernemnt in Aristotle", Rhizomata 5 (1) (2017), p. 80.

42 Ibidem, p. 83.

43 Louden, R. B., op. cit., p. 113.

44 Sellés, J. F., op. cit., p. 351.

45 Zagal, H., "Apetito recto, prudencia y verdad práctica", cit., p. 100.

46 Simon, A., op. cit., p. 83. 
verdad práctica es resultado de un apetito y un conocimiento. Más en concreto, la verdad práctica es acción según deseo recto y cálculo verdadero de medios. No es la verdad de un enunciado, sino el acierto en la acción. El deseo no es una distorsión indeseable en el conocimiento práctico, sino su condición de posibilidad. Sin deseos no conozco el mundo como medio de calmar mis apetitos. ${ }^{47}$ Con todo, a mi modo de ver, parece claro que la cuestión radica en qué queremos decir cuando caracterizamos la synesis como paso preliminar o paso en el desarrollo de la prudencia. Que la synesis sea una condición necesaria para que se dé la prudencia no significa que sea un paso hacia ella necesariamente. Por un lado, el juicio de la synesis tiene valor por sí mismo. Además, en muchas ocasiones juzgar es precisamente hacer algo, es decir, un acto de la prudencia. Por otro lado, comprender la acción prudencial como una secuencia de acciones de otras virtudes, que se van dando una detrás de otra puede no ser la mejor descripción de cómo obra el prudente, como veremos más adelante.

Queda por comentar el tercer rasgo de la relación, que afirma que la prudencia es más eminente que la synesis porque el juicio (acto de la synesis) se ordena al precepto (acto de la prudencia), y por tanto es superior a ella y no nace de ella. Y es que en realidad habla correctamente de la acción moral y productiva quien la practica. ${ }^{48} \mathrm{~A}$ la synesis le faltaría el sentido de totalidad de la prudencia. La verdad práctica se alcanza por la prudencia, no es una verdad del juicio, sino de la acción misma. ${ }^{49}$ Por el contrario, hay quien sostiene que la synesis no es un nivel inferior de la prudencia. ${ }^{50}$ De nuevo, la cuestión reside en qué entendemos por inferioridad de una respecto de la otra. Propiamente se puede hablar de superioridad sin pensar en niveles. Pero la superioridad de la prudencia resulta, en primer lugar, netamente aristotélica. A fin de cuentas, para saber lo que tenemos que hacer, hay que hacer lo que queremos saber. ${ }^{51} \mathrm{Y}$ aunque, como se dijo, en ocasiones juzgar es hacer, en otros casos no, en la medida

47 Zagal, H., "Apetito recto, prudencia y verdad práctica”, cit., pp. 105-107.

48 Sellés, J. F., op. cit., p. 351.

49 Zagal, H., "Apetito recto, prudencia y verdad práctica", cit., p. 105.

50 Simon, A., op. cit., p. 83.

51 EN, 1103a, 32-33. 
en que muchas acciones no se resuelven en juzgar. En este sentido, la perfección humana va mucho más allá del juzgar, lo que muestra a las claras la superioridad de la prudencia. En realidad, el juicio que hace algo es más bien una verdadera acción prudente que nos hace mejores o peores en sentido auténticamente moral. De todas formas, es cierto que pensar en niveles podría llevar a considerar que la prudencia no es sino la synesis junto con la decisión de obrar. No es así en la medida en que se hace necesario que el prudente ejerza otras virtudes, como la eubulia y la gnome, que son claramente diferentes de la synesis. En efecto, una cosa es la capacidad de deliberar bien y otra la de juzgar correctamente, y el juicio depende de cuáles sean los principios desde los que juzgamos. ${ }^{52}$ Pero sobre todo el riesgo consiste, a mi juicio, en pensar que primero se ejerce siempre la synesis y luego se decide actuar. En realidad, lo característico del acto prudente es que la decisión, mejor dicho, la necesidad de decidir y de actuar, preside el juicio de la synesis y la buena deliberación. La experiencia común confirma que el fin que es la acción está presente desde el primer momento. Una cosa es juzgar para decidir y otra es juzgar cuando todo va a terminar en el mero juicio. Es decir, si hay que actuar, esta necesidad de decisión preside toda la actividad intelectual del agente. Y entran en juego además otros elementos, como los afectivos (el miedo, la precipitación, por ejemplo). Por eso, en el caso de la prudencia, el juicio es muy distinto. Que podamos distinguir entre acciones y sus correspondientes hábitos, y que podamos señalar la preeminencia o superioridad de unos sobre otros, no significa que se den en una sucesión temporal necesaria como si cada uno fuera una fase del proceso de decidir. A este respecto, podemos volver ahora a la cuestión de que en ocasiones juzgar supone también una acción con relevancia ética. En efecto, cabe la calumnia, la temeridad, la promesa, las palabras de afecto o de ánimo. En definitiva, que hacemos cosas con palabras. ${ }^{53}$ De ahí que un ejemplo de

52 Jensen, S. J., "Of Gnome and Gnomes: The Virtue of Higher Discernment and the Production of Monsters", American Catholic Philosophical Quarterly 82 (2008), pp. 411-416.

53 En este punto, es conocida la referencia obligada a J. L. Austin, How to do things with words, Oxford, Clarendon Press, 1962. Hay traducción al castellano de Genaro 
PEDRO RIVAS PALÁ

synesis en puridad requeriría un juicio completamente descomprometido por parte del hablante. De ordinario lo que decimos nos hace mejores o peores, son en definitiva acciones inmanentes, cuestión diferente es si la synesis se diera también en las acciones poiéticas, como el arte o la técnica, cosa que excede nuestro propósito.

\section{EL CARÁCTER DIALÓGICO DE LA SYNESIS}

Algunos autores han insistido en que la synesis se caracteriza muy especialmente por su carácter dialógico. La mención que hace Aristóteles de que la synesis trata acerca de las cosas que son objeto de la prudencia cuando habla otro, así como el estudio etimológico del término, ha llevado a desarrollar el carácter dialógico de la misma.

En realidad, el punto de partida es un comentario de Gadamer al respecto. En efecto, Gadamer sostiene que el acto propio de la synesis es un juicio moral que no trata de uno mismo, sino de otro. Se da cuando quien juzga se desplaza por completo a la plena comprensión de la situación a juzgar, ${ }^{54}$ lo que requiere como presupuesto encontrarse en una relación de comunidad con el otro. ${ }^{55}$ El paradigma que tiene en mente es el consejo ante el problema de conciencia. Así, quien tiene synesis juzga desde una posición no externa, sino afectada, porque se une al otro, piensa con él. ${ }^{56}$ De manera que implica una especie de elemento común que da sentido al dar o recibir un consejo. Por eso, sólo los amigos pueden aconsejar. ${ }^{57}$

A partir de aquí hay quien ha insistido en que tal carácter dialógico es propio de la naturaleza de la prudencia aristotélica, porque ésta no opera aisladamente, sino que se dirige hacia lo otro, y abre

R. Carrió y Eduardo A. Rabossi, Palabras y acciones. Cómo hacer cosas con palabras, Buenos Aires, Paidós, 1971.

54 Gadamer, H-G., Verdad y método (1960), trad. de Ana Agud Aparicio y Rafael de Agapito, Salamanca, Sígueme, 1977, p. 394.

55 Ibidem, p. 395.

56 Idem.

57 Gadamer, H-G., "Hermeneutik als theoretische und praktische Aufgabe", Rechtstheorie 9 (1978). Se cita por Verdad y método II, trad. de Manuel Olasagasti, Salamanca, Sígueme, 1992, p. 306. 
el espacio a la crítica. Aunque no falte en la prudencia un elemento autorreferencial que da razón a la responsabilidad de la acción. ${ }^{58}$ En este sentido, precisamente el significado literal de synesis sería juntarse o encontrarse juntos. ${ }^{59} \mathrm{El}$ verbo del que procede (syneinai) enlaza con los verbos relacionados con el sentido de la vista que significan ver juntos o compartir el conocimiento de algo. El conjunto de palabras relacionadas muestran que el término se refiere a un tipo de uso de la inteligencia dirigido hacia e íntimamente relacionado con los otros. ${ }^{60}$ La expresión aristotélica sugiere que, en efecto, la synesis no se persigue aisladamente, sino de manera dialógica. Es entonces una habilidad de ponerse en la situación del otro, de escucharle y de dirigir al sujeto más allá de él. ${ }^{61}$

Al mismo tiempo, que la synesis juzgue a través de la doxa muestra que no se alcanza aisladamente, sino en el encuentro dialógico con los otros. ${ }^{62}$ Es entonces un comprender para decidir, comprender a los otros, aprender de su experiencia y juzgar qué es lo mejor para ellos. Por eso, el conocimiento educativo es un buen ejemplo de la synesis porque requiere auténtica comprensión humana, que demanda simpatía y empatía con el otro. ${ }^{63}$

Todavía cabe ahondar más en el elemento interpersonal. A este respecto, el uso del verbo synienai en la Metafísica de Aristóteles, con el sentido de "entender al otro", reforzaría esta perspectiva. ${ }^{64} \mathrm{Tal}$ verbo, referido a la actividad mental, indica la capacidad intelectual para unificar las cosas de modo que se alcanza en un punto a captarlas y conocerlas. ${ }^{65}$ Significa, al mismo tiempo, percibir y venir juntos.

\footnotetext{
58 Long, Ch. P., op. cit., pp. 43 y 44.

59 Ibidem, p. 46.

60 Ibidem, p. 58, nota 2.

61 Ibidem, p. 46.

62 Isidori, E., "Education as Synesis. A Hermeneutical Contribution to the Pedagogical Theory of Educational Practice", Procedia. Social and Behavioral Sciences 197 (2015), p. 533.

63 Ibidem, pp. 533 у 534.

64 Simon, A., op. cit., pp. 81 y 82.

65 Reeve, C. D. C., Aristotle on Practical Wisdom. Nicomachean Ethics VI. Translated with Introduction, Analysis and Commentary by C. D. C: Reeve, Cambridge (Mass.), Harvard University Press, p. 224.
} 
Otros usos en el propio Aristóteles tienen el sentido de escuchar o entender lo que otro dice. ${ }^{66}$

A mi juicio, hay que tener presente los usos de la palabra y su etimología, aunque haría falta mayor claridad para referirse al carácter dialógico de la synesis. Por un lado, parece claro que se trata de una forma de comprender que guarda algún tipo de analogía con el ver y el escuchar. Esta cuestión parece un tanto sorprendente a priori porque la synesis es una habilidad para juzgar, lo que supone aparentemente unir dos elementos que estaban separados a través de una operación intelectual. Mientras que ver y escuchar son acciones de los sentidos externos. Habrá ocasión de volver más adelante sobre este particular. Por otro lado, se echa en falta mayor claridad al hablar del aspecto dialógico, comunitario, interpersonal. En cierto sentido, todo conocimiento práctico tiene ese carácter, en la medida en que no estamos solos en el mundo. Nuestro conocimiento necesita de los demás y se dirige a unos bienes que se alcanzan y se comparten con los demás, aunque solamente sea porque hemos aprendido a través de los demás a comprender e incluso a sentir. Es el ser humano el que es interpersonal y dialógico. En este aspecto, no parecería aportar demasiado la insistencia en este punto. La cuestión es qué alcance tiene en el caso de la synesis. Ocurre que al mismo tiempo que seres coexistentes, nuestra posibilidad de conocer al otro es manifiestamente limitada. En cierto punto somos incomunicables. Pareciera entonces que lo característico de quien posee synesis es que logra mejor que nadie superar en lo posible esa incomunicabilidad. Es decir, que comprende más intensamente o de manera más perfecta lo que el otro piensa y vivencia. A mi modo de ver, el ejemplo que tiene en mente Gadamer cuando habla del consejo frente al problema de conciencia es solamente uno entre muchos otros y muy variados paradigmas. Isidori lleva la cuestión al terreno de la educación como ámbito que conoce y en el que se mueve. Pero podríamos extenderlo a todas las relaciones interpersonales de mayor o menor intimidad. La synesis es provechosa para comprender situaciones familiares, profesionales, de negocios, de vecindad, etcétera. En realidad, si el objeto de la razón práctica es lo contingente

66 Simon, A., op. cit., p. 82. 
y posible, lo es porque depende de la acción humana libre. Por eso, todo juicio excelente sobre tales acciones requiere de la capacidad de hacerse cargo, ponerse en la situación, comprender en definitiva tales acciones en la medida de lo posible.

\section{LA NATURALEZA DE LA SYNESIS}

Podemos afrontar ya la cuestión de cómo opera la synesis. Si bien es cierto que Gadamer, en un trabajo de 1978, sostiene que la synesis es un enjuiciamiento intuitivo, ${ }^{67}$ y Louden, en un artículo de 1997, afirma que se trata de un juicio con precisión (accurately), ${ }^{68}$ ha sido Héctor Zagal quien ha dedicado mayor empeño en caracterizar la synesis. Para ello, toma pie de algunos elementos que están presentes en el texto aristotélico. En especial, la presencia de la sensibilidad en el conocimiento prudencial que lleva a Aristóteles a afirmar que reconocer que un singular es instancia de un universal corresponde a la sensibilidad, como en el ejemplo de reconocer un triángulo. ${ }^{69}$ Es un conocimiento hasta cierto punto sensible. Por otro lado, Aristóteles afirma que al aprender se le llama comprender, y de hecho la synesis ha derivado su nombre de la acepción que tiene en el aprendizaje, porque a menudo al aprender le llamamos comprender. ${ }^{70} \mathrm{De}$ ahí que Gadamer comente que la palabra griega aparece en el contexto neutral del aprendizaje y en una proximidad intercambiable con la palabra griega que designa el aprendizaje. ${ }^{71}$ También llama la atención el hecho de que Aristóteles llame penetrantes o de perfecta comprensión a quienes poseen synesis. Y por último, trae a colación un ejemplo tangencial de los Primeros analíticos, donde Aristóteles dice que predicar de la justicia "el bien es un bien" es falso e incom-

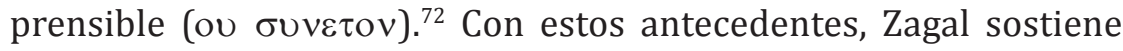
que la synesis es la captación inmediata de la eticidad de una ac-

${ }^{67}$ Gadamer, H-G., Verdad y método II, cit., p. 305.

68 Louden, R. B., op. cit., p. 113.

69 Zagal, H., “Sýnesis, euphyía y anchínoia en Aristóteles”, cit., pp. 131 y 132.

70 Ibidem, p. 134.

71 Gadamer, H-G., Verdad y método II, cit., p. 305.

72 Zagal, H., “Sýnesis, euphyía y anchínoia en Aristóteles”, cit., p. 135. 
ción. Quien la posee, aprehende rápidamente si una acción está en consonancia con la ley universal. Es más, el que tiene synesis juzga; el prudente, razona. El juicio de la synesis es una operación simple y no el resultado de un argumento. La prudencia es procesal, deliberativa, no necesariamente rápida y presta. La synesis es penetración rápida. ${ }^{73}$ Con todo, reconoce que la prudencia tampoco es puramente procesal o discursiva, porque el acto prudente presenta un momento no discursivo: el de la decisión, que es un salto que obedece a una intelección inmediata. ${ }^{74}$ También Isidori sostiene que la synesis es opuesta a la dianoia, es decir, a lo discursivo. ${ }^{75}$

Se pone de manifiesto con la synesis que en la vida moral existe o puede existir una capacidad o habilidad no discursiva: algunos ven la eticidad de una acción sin mediación del discurso racional. ${ }^{76}$ Y es que en definitiva, Aristóteles sabría que el conocimiento discursivo no puede ser explicado radicalmente sino a través del conocimiento no discursivo. Los principios de la argumentación no son argumentables ni analizables stricto sensu. Las condiciones de posibilidad del discurso racional no son objeto de análisis ni argumentación directa. ${ }^{77}$ Con todo, Zagal reconoce y lamenta la brevedad con la que Aristóteles se refiere a la cuestión y la falta de mayores explicaciones. ${ }^{78}$

A partir de aquí no hay otros comentarios que hagan referencias en este mismo sentido. Aun así, Long habla de la synesis como una habilidad para captar (to grasp) la naturaleza de una situación, pero a través de una autorreflexión crítica, no con una captación (de nuevo, grasp) inmediata de la verdad. ${ }^{79} \mathrm{Y}$ cuando trata la posibilidad de un conocimiento inmediato en la prudencia, al modo del nous, no menciona la synesis. ${ }^{80}$ Isidori sigue a Long en este punto, pero luego afirma que la synesis es una penetración rápida en la

\section{Idem.}

74 Ibidem, p. 136.

75 Isidori, E., op. cit., p. 532.

76 Zagal, H., "Sýnesis, euphyía y anchínoia en Aristóteles”, cit., p. 137.

77 Ibidem, pp. 144 y 145.

78 Ibidem, pp. 132, 133-137.

79 Long, Ch. P., op. cit., p. 46.

80 Ibidem, pp. 50-52. 
eticidad de una acción y no una operación discursiva que se pueda analizar. ${ }^{81}$ Por último, Simon insiste en que la synesis es un género de captar (to grasp) y entender que se parece al momento propio del aprendizaje en que algo se capta. ${ }^{82}$ Aunque a la vez sostiene que la synesis inquiere y razona como la prudencia. ${ }^{83}$

A mi juicio, se puede añadir, en primer lugar, la impresión que dejan todas las referencias a la etimología del término. Y es que muestra precisamente la cercanía de la palabra con los verbos ver y escuchar. Si se ponen en relación otros términos cercanos, como entender, percibir o comprender, se pone de manifiesto la relación de nuestros usos comunes de ver algo en el sentido de comprenderlo, entenderlo o captarlo. De hecho, el verbo inglés to grasp significa al mismo tiempo agarrar, asir, y también percibir, entender. Por eso, captación puede ser una buena traducción de synesis, siempre que quede claro que estamos hablando de una operación intelectual. Lo singular de este uso es que expresa muy bien que existe un momento en el que por fin se comprende o entiende algo. No hay un proceso, sino que antes no se entendía, y finalmente se capta, se ve, se encuentra, se alcanza la comprensión. Precisamente, lo característico de ver y escuchar es que no son procesos. 0 se ve o no se ve. 0 se oye o no se oye. Se ven colores o no se ve nada. Se escuchan sonidos o no se escucha nada. Cuando decimos que vemos borroso, lo que queremos decir es que no reconocemos la figura de nada, pero estamos viendo. Igualmente, la expresión oír mal quiere decir que no reconocemos palabras o música, o el significado que tenga el sonido que oímos. Emplear tales verbos referidos al conocimiento intelectual es una manera de señalar que no hay un proceso, sino que en un punto pasamos de la no comprensión a la comprensión. No deja de ser llamativo que empleamos la expresión "caer en la cuenta" para decir lo mismo. Caer tiene una manifiesta connotación de sorpresa, porque lo habitual es que uno no se cae cuando quiere ni cuando lo espera. Para eso hablamos de "dejarse caer" o de "tirarse al suelo". El elemento sorpresivo manifiesta ese pasar del cero al uno, por decirlo en términos informáticos, del no entender al entender.

\footnotetext{
81 Isidori, E., op. cit., p. 533.

82 Simon, A., op. cit., p. 81.

83 Ibidem, p. 83.
} 
En este mismo sentido cobra fuerza el hecho de que Aristóteles hable de aprendizaje para tratar de explicar la synesis. Precisamente en el aprendizaje de la matemática se vivencia ese paso del no entender al entender. Entender o comprender un determinado género de problema matemático es precisamente pasar de la incapacidad para resolverlo a la capacidad para hacerlo. Todos hemos experimentado que se trata de un momento o instante en el que captamos por fin cómo se resuelve. Y a partir de ese momento podemos resolver siempre ese tipo de operaciones. Si la resolución tiene determinados pasos, entonces esa diferencia entre comprender y no comprender se aplica a cada uno de esos pasos. Por lo anterior, se entiende que el conocimiento matemático sea ordenado, de manera que se van adquiriendo las operaciones más simples primero, que son las necesarias para resolver operaciones más complejas. Si se tratara de aplicar una técnica, bastaría seguir las instrucciones de uso. Pero en el ámbito de la matemática cada paso exige, por así decirlo, un salto en la comprensión. El ejemplo mencionado es quizá el más patente, e invoca una experiencia común. Pero son muchos otros los ámbitos donde la inteligencia pasa del no entender o no comprender a la comprensión plena ${ }^{84}$ La analogía aristotélica del aprendizaje es un motivo más para considerar plausible la interpretación de la synesis como no discursiva. En realidad, en los ejemplos de acciones que hemos puesto al principio (relaciones educativas, laborales, médicas) podemos encontrar de nuevo este paso de la no comprensión a la comprensión de una situación sin necesidad de discurso racional ni argumentación. La posibilidad y la experiencia de una respuesta acertada inmediata indican que hay una capacidad intelectual distinta de la deliberación.

Lo anterior ayuda a entender la referencia a que se trata de un conocimiento hasta cierto punto sensible. Y es que lo dicho de la vista y del oído puede decirse de todos los sentidos externos. Todavía puede comentarse algo más al respecto, como veremos, pero en este punto es suficiente resaltar la semejanza.

${ }^{84}$ En el ámbito de determinados juegos mentales, como el sudoku o los jeroglíficos, volvemos a experimentar algo similar. 
Con todo, a mi modo de ver, no se entiende del todo la necesidad de distinguir entre la synesis y la prudencia en este punto. Si el prudente posee synesis, no se entiende que necesite de la deliberación para actuar. Si ha captado la eticidad de la acción, puede obrar conforme a ella. Tal vez por eso se nos dice que la prudencia no es necesariamente rápida y presta. Ocurre en muchas ocasiones que el juicio de la synesis no es completo o no es posible que sea completo, y entonces aparece la deliberación. Es más, lo propio del prudente en esos casos es deliberar. Al mismo tiempo, como ya se ha dicho, al que tiene synesis puede faltarle prudencia o no necesitar de ella, porque no tiene que obrar de ningún modo, sino que puede permanecer en el mero juicio.

Es posible, además, añadir algunas consideraciones más de la naturaleza de la synesis. Por un lado, vale la pena señalar que lo propio de la synesis no es considerar todas las posibilidades de acción y elegir la mejor. Esto es precisamente lo que hace la deliberación. Lo característico de quien posee synesis es que ve solamente la mejor opción. Dicho de otro modo, se focaliza en lo relevante, al punto de no considerar siquiera lo irrelevante. La inmediatez de su juicio requiere precisamente ser capaz de entender lo que es relevante sin necesidad de comparar nada. Dicho de otro modo, dar con la razón que derrota cualquier otra que se presente, aunque sin necesidad de hacerlas comparecer siquiera. Por eso, quien penetra de modo rápido y certero en un problema lo hace por su capacidad para focalizarse en lo verdaderamente relevante. Cuando se le pide que dé razón de su juicio, lo que llama la atención es precisamente que en muchas ocasiones es una única razón, consistente precisamente en el elemento que se presenta a los demás como el más importante, al punto de derrotar los contrarios al mundo que uno pueda considerar.

Lo anterior nos ofrece un rasgo más. Y es que lo característico de quien posee synesis es también su capacidad para juzgar con precisión y rapidez situaciones nuevas. Dicho de otro modo, el que tiene synesis no posee necesariamente una supuestamente enorme memoria en la que encuentra la solución porque vivió anteriormente esa misma experiencia. En el fondo, en esto consiste el hábito: no en una capacidad excelente de memoria y comparación, sino en una 
forma de ser. La clásica expresión "segunda naturaleza" expresa, de manera más o menos precisa, que el agente posee un rasgo en su forma de ser que le hace excelente, y parte de esa excelencia consiste en resolver situaciones que todavía no ha pasado. En este punto vale la pena volver al ejemplo de las decisiones en el ámbito laboral y desarrollarlo más. Y es que contratar a una persona para ocupar un puesto en una organización no pasa de ser siempre una misión aparentemente imposible, por la sencilla razón de que esa persona no conoce de antemano el carácter de quienes le van a rodear, sean éstos sus subordinados, superiores, iguales o personas ajenas en forma; por ejemplo, de clientes, proveedores, competidores, en el caso de ser una empresa. Del mismo modo, lo habitual es que no conozca el pasado de dicha organización, que está formado, entre otras cosas, pero principalmente, por las vivencias de todos aquellos que le van a rodear y acabamos de mencionar. La elección del mejor indicado puede basarse en su buen desempeño en otras organizaciones, pero no deja de ser un buen desempeño en otros lugares, con personas y contextos distintos. Lo único que cabe entonces es tratar de encontrar a alguien que tenga determinada forma de ser, determinado carácter, es decir, con un conjunto de habilidades, disposiciones o excelencias que formen parte de él, y que coincidan con las que en ese momento y en ese lugar de esa organización parecieran necesitar. La persona que mejor coincida con el carácter requerido tendrá mayores posibilidades de responder con acierto a las innumerables situaciones en las que se va a encontrar con respecto a todo ese género de personas que hemos mencionado. Porque en realidad su respuesta será la que encuentre en su propio modo de ser, de una manera inmediata, en esas numerosas ocasiones en las que no es posible ni deseable la deliberación ni el consejo. Entre otras cosas, porque las situaciones que se va a enfrentar serán nuevas, y, por tanto, carece de una situación análoga en la memoria de la que poder echar mano. El ejemplo mencionado pone de manifiesto que no estamos ante una operación llevada a cabo por la memoria, sino resultado, en buena medida, de un hábito de la conducta que forma parte de una manera de ser. 


\section{LA SYNESIS EN LA TEORÍA DEL CONOCIMIENTO JURÍDICO}

Llega el momento de considerar qué relevancia tiene para una teoría del conocimiento jurídico. En este punto, se pretende ahora solamente una aproximación a los aspectos que se juzgan más relevantes, sin pretender agotar la cuestión, lo que exigiría en realidad un nuevo trabajo. Podemos partir, a mi juicio, de la superación del conocido silogismo de subsunción por una visión de la determinación del derecho que lo entiende como un proceso de acercamiento de las normas al caso y del caso a las normas. Se habla de un ir y venir de la mirada de lo uno a lo otro y de lo otro a lo uno, en el intento de seleccionar los hechos jurídicamente relevantes y de obtener las interpretaciones de las normas que conduzcan a dar una respuesta al conflicto a resolver. ${ }^{85}$ Aun sin necesidad de determinar cuál de las dos miradas es la primera, porque ambos elementos, hechos y normas, son necesarios, pareciera que cada nueva mirada supone un crecimiento en el conocimiento que se busca. De ahí que cada vez más los hechos y las normas van adquiriendo una interpretación más completa, es decir, una mejor comprensión. La conocida imagen de la espiral hermenéutica sirve para mostrar ese crecimiento y escapar de la circularidad. Ese mirar los hechos desde el punto de vista del derecho y mirar el derecho desde el punto de vista de los acontecimientos está presidido por la necesidad de tomar una decisión vinculante. Por eso es un acto de la prudencia, porque desde su origen lo guía el propósito de dar una respuesta que crea un curso de acción obligatorio, bien es verdad que para otros. En este punto, aunque excede nuestro propósito, parece que es la excelencia de la buena deliberación lo que preside el razonamiento del jurista. Ahora bien, es fácil advertir que ese ir y venir se detiene en un momento dado. Cabe preguntarse por qué se detiene en ese momento preciso, y la respuesta evidente es porque el intérprete no necesita ir más allá porque cree haber alcanzado la solución. Parece claro que no ha

85 La expresión original es de Engisch (Engisch, K., Logische Studien zur Gesetzesanwendung, 3a. ed., Heidelberg, Carl Winter-Universitätsverlag, 1963, p. 15) y su traducción, de Rodríguez Molinero (Rodríguez Molinero, M., Introducción a la ciencia del derecho, Salamanca, Librería Cervantes, 1998, p. 210, nota 17). 
encontrado la solución a través de un proceso meramente deductivo ni demostrativo. Pero, si no ha sido a través de una deducción, ¿cómo se ha hecho presente tal solución? ¿De qué manera ha sido encontrada o se le ha aparecido? A mi modo de ver, es precisamente la excelencia que Aristóteles denomina synesis la que lo explica. Lo que se ha activado es esa capacidad para penetrar de manera rápida y precisa en la juridicidad de una acción, o mejor dicho de un conjunto de acciones. Es evidente que unos necesitan más tiempo que otros para alcanzar la solución que a su entender resulta correcta. El motivo es simplemente que unos poseen dicha excelencia en mayor grado que otros, habitualmente referida a una rama o a un sector de la realidad jurídica. Cuanta más synesis tiene el intérprete, menos necesita del ir y venir para encontrar la solución. Ocurre en el ámbito del derecho que, una vez encontrada, es preciso construir una fundamentación lo más completa y clara que se considere necesaria. Por eso, el razonamiento jurídico tiene un momento productivo, que no es el caso considerar. En ese momento productivo se puede comprobar si lo que se le presentó al intérprete como solución es tal o no. Es decir, es un momento donde la deliberación se hace presente de nuevo. Pero lo único que puede detener el proceso de búsqueda es un hallazgo que marca la diferencia entre un no tener solución y tenerla. Como se ve, de intento evito emplear expresiones con carga metafórica, como la del salto a la solución.

Para encontrar la respuesta al caso tiene que darse al menos un momento donde actúa la synesis, aunque se puede imaginar que pueda ocurrir en el curso de la deliberación que haya otros momentos similares aunque no definitivos, como cuando se decida abandonar una posible interpretación o se descubran elementos relevantes que antes no se habían percibido. Más aún, la decisión del intérprete de encarar los hechos desde una determinada perspectiva, y no desde las otras numerosas posibilidades que le ofrece el derecho, supone también un juicio de la synesis. Igualmente, las casi innumerables interpretaciones posibles de una norma o de un hecho que el intérprete ni siquiera toma en consideración son de nuevo consecuencia de un juicio de la synesis, que le lleva, como vimos, a no considerar aspectos que el lego en el derecho o el más obtuso tal vez necesitaría valorar. 
Al margen de lo anterior, tal vez donde se hace más presente la realidad de la synesis sea en los denominados casos fáciles, donde, por ejemplo, el intérprete advierte que si ha llegado a sus manos es más por una cuestión de estrategia procesal o de simple empecinamiento de una de las partes. En esas situaciones, la impresión de la no necesidad de deliberación puede ser más fuerte. Pero, como se vio, en todos los casos hay al menos un momento que no es deliberativo, sino que supone un comprender o entender lo que hasta hace un instante no se comprendía o entendía. Es decir, un momento que reproduce lo que ocurre, como vimos, en el aprendizaje matemático, en la adquisición de la capacidad para resolver un tipo de problemas que era desconocido para el sujeto.

Llegados a este punto, son muchos los aspectos a considerar para trabajos posteriores. Por ejemplo, la pregunta por cómo se adquiere la synesis. Igualmente, cabe interrogarse si puede ser aprendida, o incluso si puede ser enseñada. Y en ese sentido, quedan abiertas otras cuestiones, como la posible presencia de otros aspectos no discursivos e igualmente racionales.

\section{EXCURSUS: UNA POSIBLE TRADUCCIÓN}

Para terminar, corresponde hacer un breve excursus sobre la traducción del término synesis. En un trabajo reciente se ha señalado que la mayoría de los términos que Aristóteles emplea en el libro VI de la Ética a Nicómaco no son innovaciones lingüísticas, sino términos bien conocidos a través de las obras de Platón y de otros filósofos, así como de retóricos y literatos. Aunque como la ética no tiene un objeto tan estricto como otros objetos, tampoco el lenguaje de la ética es tan estricto como el de la lógica o la matemática. ${ }^{86}$ Con todo, el problema de las traducciones de esta palabra reside en que se emplean términos que tienen muchos otros significados y que se usan ordinariamente con otro sentido. Las versiones más conocidas en cas-

86 Solopova M. A., "Aristotle on the Intellectual Virtues: On the Meaning of the Notions of Consideration (gnome) and Consideration (syngnomé) in Nicomachean Ethics", Russian Studies in Philosophy 54 (6) (2016), pp. 520 y 521. 
tellano lo traducen como "entendimiento", ${ }^{87}$ y como, "inteligencia". ${ }^{88}$ El comentario de Tomás de Aquino que se mencionó transcribe en principio la palabra synesis, aunque en otra obra se anima a emplear la traducción de sensatus, que podría llevar a traducir synesis por sensatez. ${ }^{89} \mathrm{Si}$ acudimos a algunas clásicas traducciones inglesas, encontramos quienes lo traducen por intelligence, ${ }^{90}$ quien emplea understanding ${ }^{91}$ y quien usa judgement. ${ }^{92}$

A mi modo de ver, poseemos en castellano un término que recoge bien lo que se ha venido diciendo de la synesis. Tiene además la ventaja de tener un único significado y de ser de uso común, aunque tal vez no demasiado frecuente. Por otro lado, la etimología latina del término encaja correctamente con la caracterización que hemos hecho de la synesis, y que remite además a la expresión griega. Y es que poseemos una palabra que tiene como raíz el verbo latino spicere, que significa "ver" y "mirar". Además, esa misma palabra tiene un prefijo, que significa en latín al mismo tiempo "a través de" y "por completo". Por último, el adjetivo que refiere a quien la posee tiene una terminación (-az), también de origen latina, que indica una fuerte tendencia (como en locuaz, veraz, voraz, feraz). Me refiero al término "perspicacia", cualidad de "perspicaz". Si unimos lo dicho hasta ahora, se entiende que hace referencia a ver por completo, a través de y con intensidad. La insistencia en que se trata de una operación intelectual asimilable a la visión, que penetra en la realidad de las cosas, logrando un conocimiento completo e intenso, queda bien reflejada en la palabra "perspicacia". Sinónimo de ésta es "agudeza", pero este término tiene otros muchos sentidos más usuales en el momento presente, donde casi nadie la entiende

87 Trad. de Julián Marías y María de Araujo, Madrid, Instituto de Estudios Políticos, 1949, con numerosas reimpresiones; y trad. de Julio Pallí Bonet, Madrid, Gredos, 1985.

88 Trad. de José Luis Calvo Martínez, Madrid Alianza, 2001.

89 S. Th., II-II, q. 51, a. 3. c.

90 Trad. de F. H. Peters, London, Kegan Paul, 1893; y trad. de D. P. Chasse, London, Routledge, 1910.

91 Trad. de D. Ross, revisada por L. Brown, Oxford, Oxford University Press, 2009.

92 Trad. de R. Crisp, Cambridge University Press, 2004. Pueden encontarse más ejemplos en el trabajo de Rodrigues Montes D’Oca, F., op. cit., nota 1. 
con el sentido de perspicacia. Además, carece de la fuerza etimológica de "perspicacia".

\section{BIBLIOGRAFÍA}

Aquino, Tomás de, Sententia libri Ethicorum.

Aquino, Tomás de, Summa Theologiae.

Aquino, Tomás de, Scriptum super Sententiis.

ARIstóteles, Ética a Nicómaco, se emplea la trad. de Julián Marías y María de Araujo (1949), Madrid, Centro de Estudios Constitucionales, 1994.

Aristotle, Nicomachean Ethics, trad. de F. H. Peters, London, Kegan Paul, 1893.

Aristotle, Nicomachean Ethics, trad. de D. P. Chasse, London, Routledge, 1910.

Aristotle, Nicomachean Ethics, trad. de D. Ross, revisada por L. Brown, Oxford, Oxford University Press, 2009.

ARISTOTLE, Nicomachean Ethics, trad. de R. Crisp, Cambridge University Press, 2004.

\section{Bibliografía secundaria}

Austin, John L., How to do Things with Words, Oxford, Clarendon Press, 1962. Hay trad. al castellano de Genaro R. Carrió y Eduardo A. Rabossi, Palabras y acciones. Cómo hacer cosas con palabras, Buenos Aires, Editorial Paidós, 1971.

ENGISCH, Karl, Logische Studien zur Gesetzesanwendung, 3a. ed., Heidelberg, Carl Winter Universitätsverlag, 1963.

Gadamer, Hans-Georg, Verdad y método (1960), trad. de Ana Agud Aparicio y Rafael de Agapito, Salamanca, Sígueme, 1977.

GADAMER, Hans-Georg, "Hermeneutik als theoretische und praktische Aufgabe", Rechtstheorie 9, Heidelberg, 1978. Se cita por Verdad y método II, trad. de Manuel Olasagasti, Salamanca, Sígueme, 1992. 
PEDRO RIVAS PALÁ

GeHLEn, Arnold, El hombre: su naturaleza y su lugar en el mundo (1940), trad. de Fernando-Carlos Vevia Romero, Salamanca, Sígueme, 1987.

IsIDori, Emanuele, "Education as Synesis. A Hermeneutical Contribution to the Pedagogical Theory of Educational Practice", Procedia. Social and Behavioral Sciences 197, 2015.

Jensen, Steven J., "Of Gnome and Gnomes: The Virtue of Higher Discernment and the Production of Monsters", American Catholic Philosophical Quarterly 82, St. Paul-Minneapolis, 2008.

LonG, Christopher P., "The Ontological Reappropiation of Phronesis", Continental Philosophy Review 35, Stony Brook, 2002.

Louden, Robert B., "What is Moral Authority? Eubulía, synesis y gnome vs. frónesis", Ancient Philosophy 17, Pittsburg, 1997.

ReEve, C. D. C., Aristotle on Practical Wisdom. Nicomachean Ethics VI, Translated with Introduction, Analysis and Commentary by C. D. C: Reeve, Cambridge, Harvard University Press.

Rodrigues Montes D’OCA, Fernando, "Prudencia e astucia na ética aristotélica: um estudo sobre as capacidades intelectuais que acompanham a prudencia", Controversia 5 (1), Sao Leopoldo, 2009.

SEllÉs, Juan Fernando, Los hábitos intelectuales según Tomás de Aquino, Pamplona, EUNSA, 2008.

Simon, Attila, "Sunesis as Ethical Discernemnt in Aristotle", Rhizomata 5, Budapest, (1), 2017.

Solopova, Maria A., "Aristotle on the Intellectual Virtues: On the Meaning of the Notions of Consideration (gnome) and Consideration (syngnomé) in Nicomachean Ethics", Russian Studies in Philosophy 54 (6), 2016.

ZAGAL, Héctor, "Sýnesis, euphyía y anchínoia en Aristóteles. Algunas habilidades para el conocimiento del singular", Anuario Filosófico 32, Pamplona, 1999.

ZAGAL, Héctor, "Apetito recto, prudencia y verdad práctica. Las pautas de la eupraxía en la Nicomáquea", Metafísica y Persona 5 (9), Málaga, 2013. 